\title{
Reliability and flexural behavior of triangular and T-reinforced concrete beams
}

\author{
Mohammed S. Al-Ansari ${ }^{1}$
}

Received: 8 May 2014/ Accepted: 12 October 2015/Published online: 13 November 2015

(c) The Author(s) 2015. This article is published with open access at Springerlink.com

\begin{abstract}
The paper studied the behavior of reinforced concrete triangular and T-beams. Three reinforced concrete beams were tested experimentally and analyzed analytically using the finite element method. Their reliability was also assessed using the reliability index approach. The results showed that the finite element vertical displacements compared well with those obtained experimentally. They also showed that the vertical displacements obtained using the finite element method were larger than those obtained experimentally. This is a strong indication that the finite element results were conservative and reliable. The results showed that the triangular beams exhibited higher ductility at failure than did the T-beam. The plastic deformations at failure of the triangular beams were higher than that of the T-beam. This is a strong indication of the higher ductility of the triangular beams compared to the T-beam. Triangular beams exhibited smaller cracks than did T-beams for equal areas of steel and concrete. The design moment strengths $M_{c}$ computed using the American Concrete Institute (ACI) design formulation were safe and close to those computed using experimental results. The experimental results validated the reliability analysis results, which stated that the triangular beams are more reliable than T-beams for equal areas of steel and concrete.
\end{abstract}

Mohammed S. Al-Ansari

m.alansari@qu.edu.qa

1 Department of Civil and Architectural Engineering, University of Qatar, P.O. Box 2713, Doha, Qatar
Keywords Concrete beams - Experimental testing . Finite element $\cdot$ Nonlinear analysis - Reliability index

\section{Introduction}

The majority of structures built worldwide are made of reinforced concrete. Most of these structures use beams as a structural elements to resist applied loads. The reliability and response of these structural components were studied using the reliability index $\beta$ and finite element analysis, respectively (Saifullah et al. 2011; Vecchio and Shim 2004). The reliability index $\beta$ measures the level of reliability of the beams based on their response to applied loads and according to their design codes. The reliability index chart is very useful for determining the beam strength capacity for a desired level of reliability (Al-Ansari 2013a). The behavior of reinforced concrete structural elements was also studied using experimental testing. Concrete beams of different sections were analyzed for safety, stability, deformation, and crack formation based on ACI Ultimate Design Method [Lu et al. 1994; Borse and Dubey 2013; American Concrete Institute (ACI) 2008; McCormac and Brown 2009]. Experimental testing is time consuming and costly while finite element analysis is faster and less expensive. Finite element models have been developed for reinforced concrete beams to study their response at various load stages (Nahvi and Jabbari 2005). The objective of this paper is to study the flexural behavior of triangular and T-reinforced concrete beams subjected to center point loadings. The experimental load-deflection results were compared with those obtained using a non-linear finite element analysis (Bentley System Inc. 2009). The reliability of the beams was also assessed using the reliability index approach. 


\section{Reliability formulation}

A beam fails when its resistance is less than the action caused by the applied loads. The beam resistance and action are computed using the design strength $M_{\mathrm{c}}$ and the external bending moment $M_{\mathrm{e}}$, respectively. Figure 1 shows the compressive and tensile cross sectional areas for and triangular and T-beams.

The beam limit state function is given by the following equation:

$G\left(A_{\mathrm{s}}, f_{\mathrm{c}}^{\prime}, f_{\mathrm{y}}, M_{\mathrm{e}}\right)=M_{\mathrm{c}}-M_{\mathrm{e}}$

where $M_{\mathrm{c}}=$ design strength, $M_{\mathrm{e}}=$ external bending moment, $A_{\mathrm{s}}=$ tensile steel area, $f_{\mathrm{y}}=$ reinforcing steel yield strength, and $f_{\mathrm{c}}^{\prime}=$ concrete compressive strength.

The triangular beam limit state function is given by the following equation:

$G\left(A_{\mathrm{s}}, f_{\mathrm{c}}^{\prime}, f_{\mathrm{y}}, M_{\mathrm{e}}\right)=\phi \mu_{A_{\mathrm{s}}} \mu_{f_{\mathrm{y}}}\left(d-\frac{2}{3} \sqrt{\frac{\frac{\mu_{A_{s}} \mu_{\mathrm{f}_{\mathrm{y}}}}{0.85 \mu_{f_{\mathrm{c}}^{\prime}}}}{0.5 \frac{b}{h}}}\right)-\mu_{M_{\mathrm{e}}}$

where $\phi=$ bending reduction factor, $b=$ beam width, $d=$ beam effective depth, $h=$ beam depth, $\mu_{f_{\mathrm{y}}}=$ mean value of $f_{\mathrm{y}} ; \mu_{f_{\mathrm{c}}^{\prime}}=$ mean value of $f_{\mathrm{c}}^{\prime}, \mu_{A_{\mathrm{s}}}=$ mean value of $A_{\mathrm{s}}$, and $\mu_{M_{\mathrm{e}}}=$ mean value of $M_{\mathrm{e}}$.

Because of its nonlinearity, the limit state function is linearized using the Taylor series expansion about the mean value using the following equation (Nowak and Collins 2013):

$$
\begin{gathered}
G\left(A_{\mathrm{s}}, f_{\mathrm{c}}^{\prime}, f_{\mathrm{y}}, M_{\mathrm{e}}\right)=\left(\phi \mu_{A_{\mathrm{s}}} \mu_{f_{\mathrm{y}}}\left(d-\frac{2}{3} \sqrt{\frac{\frac{\mu_{A_{\mathrm{s}}} \mu_{\mathrm{f}_{\mathrm{y}}}}{0.85 \mu_{f_{\mathrm{c}}^{\prime}}}}{0.5 \frac{b}{h}}}\right)-\mu_{M_{\mathrm{e}}}\right) \\
+\left(A_{\mathrm{s}}-\mu_{A_{\mathrm{s}}}\right) \frac{\mathrm{d} G}{\mathrm{~d} A_{\mathrm{s}}}+\left(f_{\mathrm{y}}-\mu_{f_{\mathrm{y}}}\right) \frac{d G}{d_{f_{\mathrm{y}}}}+\left(f_{\mathrm{c}}^{\prime}-\mu_{f_{\mathrm{c}}^{\prime}}\right) \frac{\mathrm{d} G}{\mathrm{~d} f_{\mathrm{c}}^{\prime}} \\
+\left(f_{\mathrm{c}}^{\prime}-\mu_{f_{\mathrm{c}}^{\prime}}\right) \frac{\mathrm{d} G}{\mathrm{~d} f_{\mathrm{c}}^{\prime}}
\end{gathered}
$$

Fig. 1 Compressive and tensile section areas for $\mathrm{T}$ - and

Triangular beams
The reliability index $\beta$ of the linear function is given by the following equation:

$\beta=\frac{G\left(A_{\mathrm{s}}, f_{\mathrm{c}}^{\prime}, f_{\mathrm{y}}, M_{e}\right)}{\sqrt{\left(\sigma_{A_{\mathrm{s}}} a_{1}\right)^{2}+} \sqrt{\left(\sigma_{f_{\mathrm{y}}} a_{2}\right)^{2}}+\sqrt{\left(\sigma_{f_{\mathrm{c}}^{\prime}} a_{3}\right)^{2}}+\sqrt{\left(\sigma_{M_{\mathrm{e}}} a_{4}\right)^{2}}}$

where $\sigma_{A_{\mathrm{s}}}=$ standard deviation of $A_{\mathrm{s}}, \sigma_{f_{\mathrm{v}}}=$ standard deviation of $f_{\mathrm{y}}, \sigma_{f_{\mathrm{c}}^{\prime}}=$ standard deviation of $f_{\mathrm{c}}^{\prime}$; and $\sigma_{M_{\mathrm{e}}}=$ standard deviation of $M_{\mathrm{e}}$. The parameters $a_{1}, a_{2}, a_{3}$, and $a_{4}$ are given by the following equations, respectively:

$a_{1}=\frac{\partial G}{\partial A_{\mathrm{s}}}\left(\phi A_{\mathrm{s}} f_{\mathrm{y}}\left(d-\frac{2}{3} \sqrt{\frac{\frac{A_{\mathrm{s}} f_{\mathrm{y}}}{0.85 f_{\mathrm{c}}^{\prime}}}{0.5 \frac{b}{h}}}\right)-M_{\mathrm{e}}\right)$

$a_{2}=\frac{\partial G}{\partial f_{\mathrm{y}}}\left(\phi A_{\mathrm{s}} f_{\mathrm{y}}\left(d-\frac{2}{3} \sqrt{\frac{\frac{A s f_{\mathrm{y}}}{0.85 f_{\mathrm{c}}^{\prime}}}{0.5 \frac{b}{h}}}\right)-M_{\mathrm{e}}\right)$

$a_{3}=\frac{\partial G}{\partial f_{\mathrm{c}}^{\prime}}\left(\phi A_{\mathrm{s}} f_{\mathrm{y}}\left(d-\frac{2}{3} \sqrt{\frac{A_{\mathrm{s}} f_{\mathrm{y}}}{0.85 f_{\mathrm{c}}^{\prime}}}\right)-M_{\mathrm{e}}\right)$

$a_{4}=\frac{\partial G}{\partial M_{\mathrm{e}}}\left(\phi A_{\mathrm{s}} f_{\mathrm{y}}\left(d-\frac{2}{3} \sqrt{\frac{\frac{A_{\mathrm{s}} f_{\mathrm{y}}}{0.85 f_{\mathrm{c}}^{\prime}}}{0.5 \frac{b}{h}}}\right)-M_{\mathrm{e}}\right)$

The standard deviation $\sigma$ is equal to the product of the mean value $\mu$ and the coefficient of variation $V$. The formulation estimates the reliability index $\beta$ of triangular beams when subjected to flexural loads, based on their resistance to applied loads (Table 1; Fig. 2).

The limit state function of a T-beam with its neutral axis lying in the flange is given by the following equation:

$G\left(A_{\mathrm{s}}, f_{\mathrm{c}}^{\prime}, f_{\mathrm{y}}, M_{\mathrm{e}}\right)=\phi \mu_{A_{\mathrm{s}}} \mu_{f_{\mathrm{y}}}\left(d-\frac{1}{2} \frac{\mu_{A_{\mathrm{s}}} \mu_{f_{\mathrm{y}}}}{0.85 \mathrm{~b} \mu_{f_{\mathrm{c}}^{\prime}}}\right)-\mu_{M_{\mathrm{e}}}$

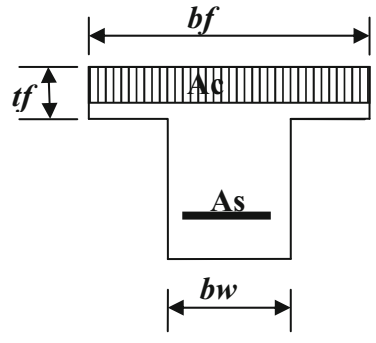

Neutral axis in flange

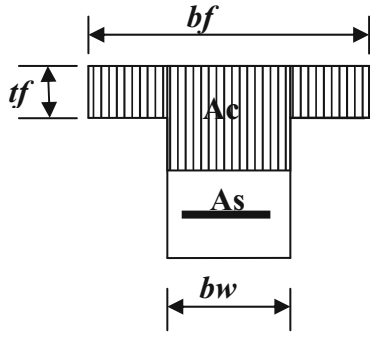

Neutral axis in web

Triangular Beam

T - Beam 
Table 1 Triangular beam analysis results

\begin{tabular}{|c|c|c|c|c|c|c|c|c|c|}
\hline \multirow[t]{2}{*}{$M_{\mathrm{e}}(\mathrm{kN} \mathrm{m})$} & \multicolumn{6}{|c|}{ Beam data } & \multirow[t]{2}{*}{$M_{\mathrm{c}}(\mathrm{kN} \mathrm{m})$} & \multirow[t]{2}{*}{$\beta$} & \multirow{2}{*}{$\begin{array}{l}\text { Safety } \\
\text { percentage }(\%)\end{array}$} \\
\hline & $f_{\mathrm{c}}(\mathrm{MPa})$ & $f_{\mathrm{y}}(\mathrm{MPa})$ & $b(\mathrm{~mm})$ & $h(\mathrm{~mm})$ & $d(\mathrm{~mm})$ & $A_{\mathrm{s}}\left(\mathrm{mm}^{2}\right)$ & & & \\
\hline 17 & 420 & 30 & 200 & 400 & 300 & 250 & 20 & 1.0 & 15 \\
\hline 184 & 420 & 30 & 300 & 950 & 800 & 1050 & 230 & 1.5 & 20 \\
\hline 390 & 420 & 30 & 400 & 1300 & 1100 & 1700 & 524 & 2.0 & 26 \\
\hline 640 & 420 & 30 & 400 & 1600 & 1300 & 2100 & 753 & 1.0 & 15 \\
\hline 890 & 420 & 30 & 600 & 1600 & 1400 & 3000 & 1200 & 2.0 & 26 \\
\hline
\end{tabular}

Fig. 2 Triangular beam reliability index

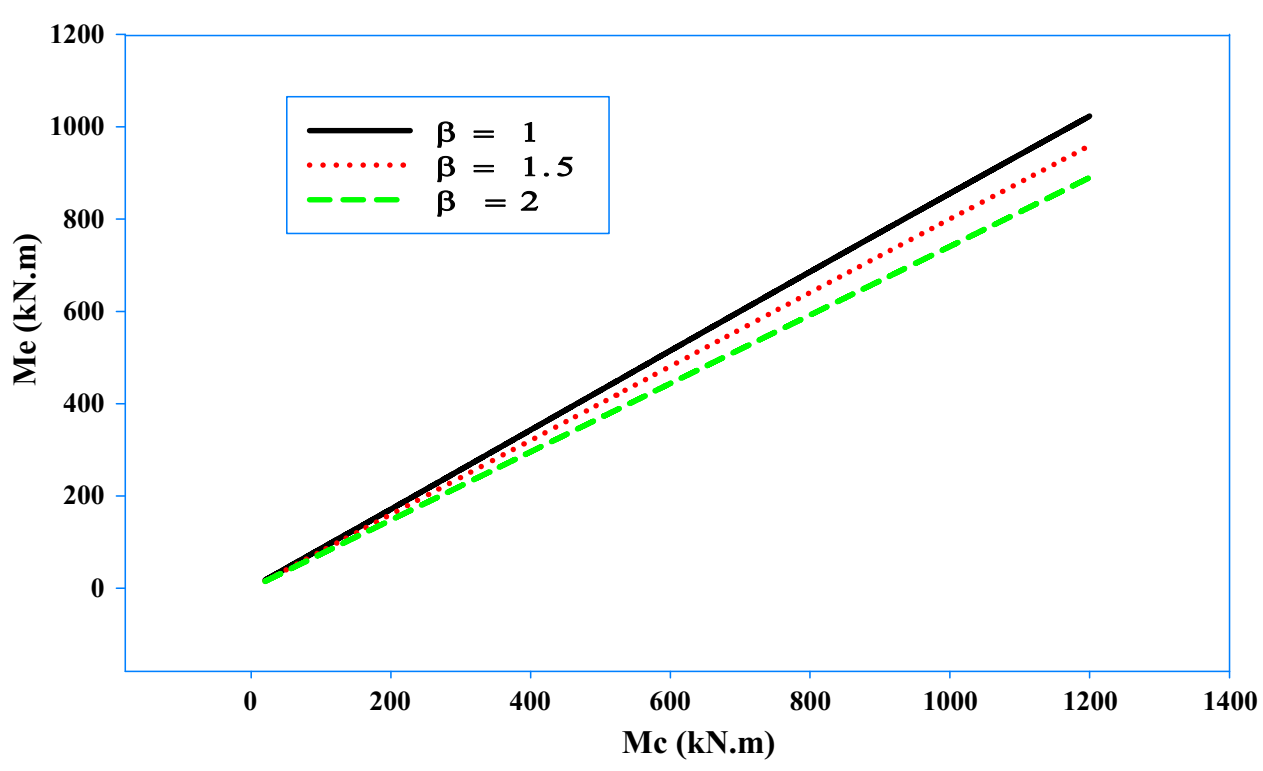

Table 2 T-beam analysis results (neutral axis in flange)

\begin{tabular}{|c|c|c|c|c|c|c|c|c|c|c|}
\hline \multirow[t]{2}{*}{$M_{\mathrm{e}}(\mathrm{kN} \mathrm{m})$} & \multicolumn{7}{|c|}{ Beam data } & \multirow[t]{2}{*}{$M_{\mathrm{c}}(\mathrm{kN} \mathrm{m})$} & \multirow[t]{2}{*}{$\beta$} & \multirow{2}{*}{$\begin{array}{l}\text { Safety } \\
\text { percentage }(\%)\end{array}$} \\
\hline & $f_{\mathrm{c}}(\mathrm{MPa})$ & $f_{\mathrm{y}}(\mathrm{MPa})$ & $b_{\mathrm{w}}(\mathrm{mm})$ & $b_{\mathrm{f}}(\mathrm{mm})$ & $t_{\mathrm{f}}(\mathrm{mm})$ & $d(\mathrm{~mm})$ & $A_{\mathrm{s}}\left(\mathrm{mm}^{2}\right)$ & & & \\
\hline 20 & 30 & 420 & 200 & 300 & 100 & 300 & 250 & 27.7 & 2.0 & 28 \\
\hline 212 & 30 & 420 & 200 & 450 & 100 & 750 & 900 & 250 & 1.0 & 15 \\
\hline 406 & 30 & 420 & 200 & 450 & 100 & 1000 & 1400 & 516 & 1.5 & 21 \\
\hline 820 & 30 & 420 & 200 & 450 & 100 & 1400 & 2200 & 1131 & 2.0 & 27 \\
\hline 1230 & 30 & 420 & 200 & 500 & 100 & 1600 & 2450 & 1440 & 1.0 & 15 \\
\hline
\end{tabular}

After function linearization and constant determination, the reliability index $\beta$ is obtained using the following equation:

$\beta=\frac{F\left(A_{\mathrm{s}}, f_{\mathrm{c}}^{\prime}, f_{\mathrm{y}}, M_{\mathrm{e}}\right)}{\sqrt{\left(\sigma_{A_{\mathrm{s}}} a_{1}\right)^{2}+} \sqrt{\left(\sigma f_{\mathrm{y}} a_{2}\right)^{2}}+\sqrt{\left(\sigma_{f_{\mathrm{c}}^{\prime}} a_{3}\right)^{2}}+\sqrt{\left(\sigma_{M_{\mathrm{e}}} a_{4}\right)^{2}}}$

The formulation allows the estimation of the reliability index $\beta$ of a T-beam with the neutral axis in the flange when subjected to flexural loads (Table 2; Fig. 3).
The limit state function of a T-beam with its neutral axis lying in the web is given by the following equation:

$W\left(A_{\mathrm{s}}, f_{\mathrm{c}}^{\prime}, f_{\mathrm{y}}, M_{\mathrm{e}}\right)=\phi \mu_{A_{\mathrm{s}}} \mu_{f_{\mathrm{y}}}(d-y)-\mu_{M_{\mathrm{e}}}$

where $A_{\mathrm{f}}=$ flange crosssectional area, $A_{\mathrm{c}}=$ compressive crosssectional area, $t_{\mathrm{f}}=$ flange thickness, $b_{\mathrm{w}}=$ web width . The location of the neutral axis $y$ is given by the following equation:

$y=\frac{A_{\mathrm{f}} \frac{t_{\mathrm{f}}}{2}+\left(A_{\mathrm{c}}-A_{\mathrm{f}}\right)\left(0.5 \frac{A_{\mathrm{c}}-A_{\mathrm{f}}}{b_{\mathrm{w}}}+t_{\mathrm{f}}\right)}{A_{\mathrm{c}}}$ 
Fig. 3 Reliability index of T-beams with neutral axis in the flange

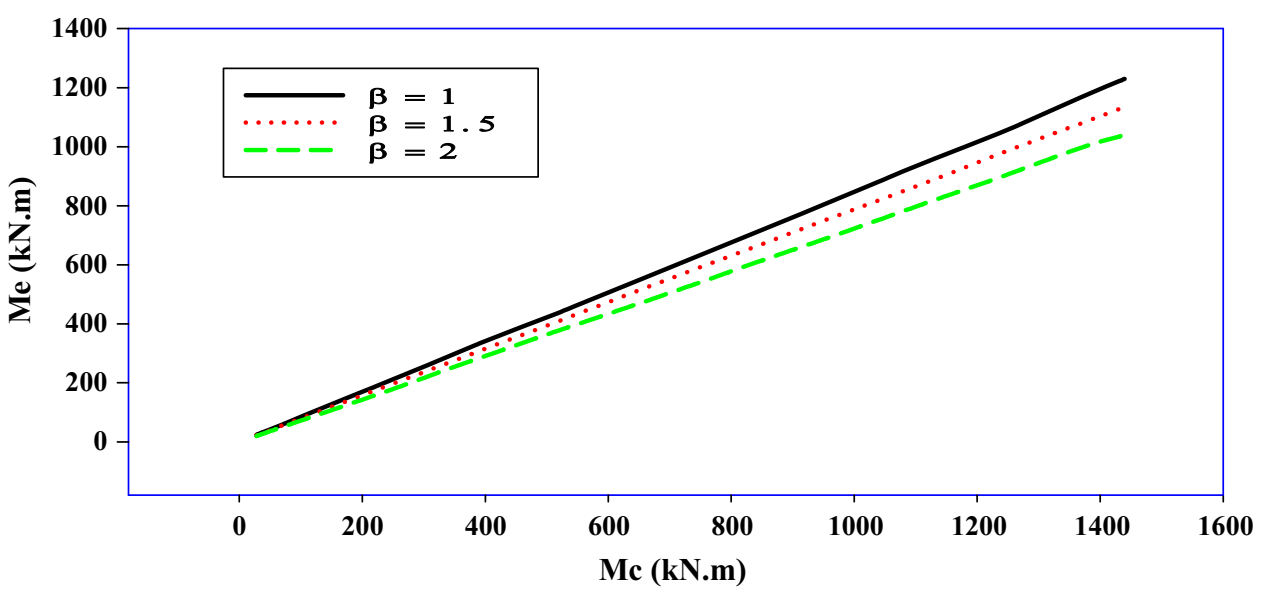

Table 3 T-beam analysis results (neutral axis in web)

\begin{tabular}{|c|c|c|c|c|c|c|c|c|c|c|}
\hline \multirow[t]{2}{*}{$M_{\mathrm{e}}(\mathrm{kN} \mathrm{m})$} & \multicolumn{7}{|c|}{ Beam data } & \multirow[t]{2}{*}{$M_{\mathrm{c}}(\mathrm{kN} \mathrm{m})$} & \multirow[t]{2}{*}{$\beta$} & \multirow{2}{*}{$\begin{array}{l}\text { Safety } \\
\text { percentage }(\%)\end{array}$} \\
\hline & $f_{\mathrm{c}}(\mathrm{MPa})$ & $f_{\mathrm{y}}(\mathrm{MPa})$ & $b_{\mathrm{w}}(\mathrm{mm})$ & $b_{\mathrm{f}}(\mathrm{mm})$ & $t_{\mathrm{f}}(\mathrm{mm})$ & $d(\mathrm{~mm})$ & $A_{\mathrm{s}}\left(\mathrm{mm}^{2}\right)$ & & & \\
\hline 218 & 30 & 420 & 250 & 300 & 100 & 400 & 2000 & 261 & 1.0 & 16 \\
\hline 415 & 30 & 420 & 300 & 400 & 100 & 600 & 2600 & 537 & 1.5 & 23 \\
\hline 626 & 30 & 420 & 300 & 500 & 100 & 800 & 3100 & 878 & 2.0 & 29 \\
\hline 1350 & 30 & 420 & 400 & 600 & 100 & 1200 & 3700 & 1607 & 1.0 & 16 \\
\hline 1584 & 30 & 420 & 400 & 600 & 100 & 1500 & 3700 & 2027 & 1.5 & 22 \\
\hline 1810 & 30 & 420 & 500 & 700 & 100 & 1600 & 4300 & 2518 & 2.0 & 28 \\
\hline
\end{tabular}

After function linearization and constant determination, the reliability index $\beta$ is obtained using the following equation:

$\beta=\frac{W\left(A_{\mathrm{s}}, f_{\mathrm{c}}^{\prime}, f_{\mathrm{y}}, M_{\mathrm{e}}\right)}{\sqrt{\left(\sigma_{A_{\mathrm{s}}} a_{1}\right)^{2}+} \sqrt{\left(\sigma_{f_{\mathrm{y}}} a_{2}\right)^{2}}+\sqrt{\left(\sigma_{f_{\mathrm{c}}^{\prime}} a_{3}\right)^{2}}+\sqrt{\left(\sigma_{M_{\mathrm{e}}} a_{4}\right)^{2}}}$

The reliability index $\beta$ is calculated for a T-beam with its neutral axis in the web (Table 3; Fig. 4).

\section{Experimental testing}

Three reinforced concrete beams (two triangular beams and one T-beam) were tested at Qatar University to study their behavior under applied center loads (Instron 2003; AlAnsari 2013b). The Instron HDX150 machine was used in the testing as shown in Fig. 5. The equipment has a $1500-\mathrm{kN}$-load-capacity testing in bending, compression, and shear. Figure 6 shows the schematic representation of the test setup. The three beams, which had a length of 2 meters, were prepared using a 33-MPa-compressivestrength concrete material. They were reinforced with two tensile T-12 steel bars. The shear reinforcement consisted of @8 stirrups spaced at a distance of $200 \mathrm{~mm}$. The reinforcing steel bars had yield strength of $550 \mathrm{MPa}$. The beam cross sectional dimensions are summarized in Table 4. The concrete mix design is summarized in Table 5.

The testing machine provides an output data set that includes time, flexural load, stress and strain, and displacement. Table 6 shows a sample of the testing machine output set.

The Triangular I, Triangular II, and T-beams collapsed under concentrated loads of 34,45 , and $41 \mathrm{kN}$, respectively. Figure 7 shows the crack pattern and deformed shape of the beams after collapse.

The deflection of the beams was obtained from the output that was provided by the testing machine. Table 7 summarizes the failure load and deflection at collapse for the three beams. On the other hand, Fig. 8 shows the loaddeflection response for the three beams.

The results show that the triangular beams exhibited higher ductility at failure than did the T-beam. The displacements of the triangular beams I and II at collapse were approximately 26 and $21 \mathrm{~mm}$, respectively. On the other hand, the displacement of the T-beam at collapse was approximately $17 \mathrm{~mm}$. This shows that the plastic deformation at failure of the triangular beams was higher than that of the T-beam. This is a strong indication of the higher ductility of the triangular beams compared to the T-beam. 
Fig. 4 Reliability index of T-beams with neutral axis in the web

Fig. 5 Instron HDX1500 static universal testing system
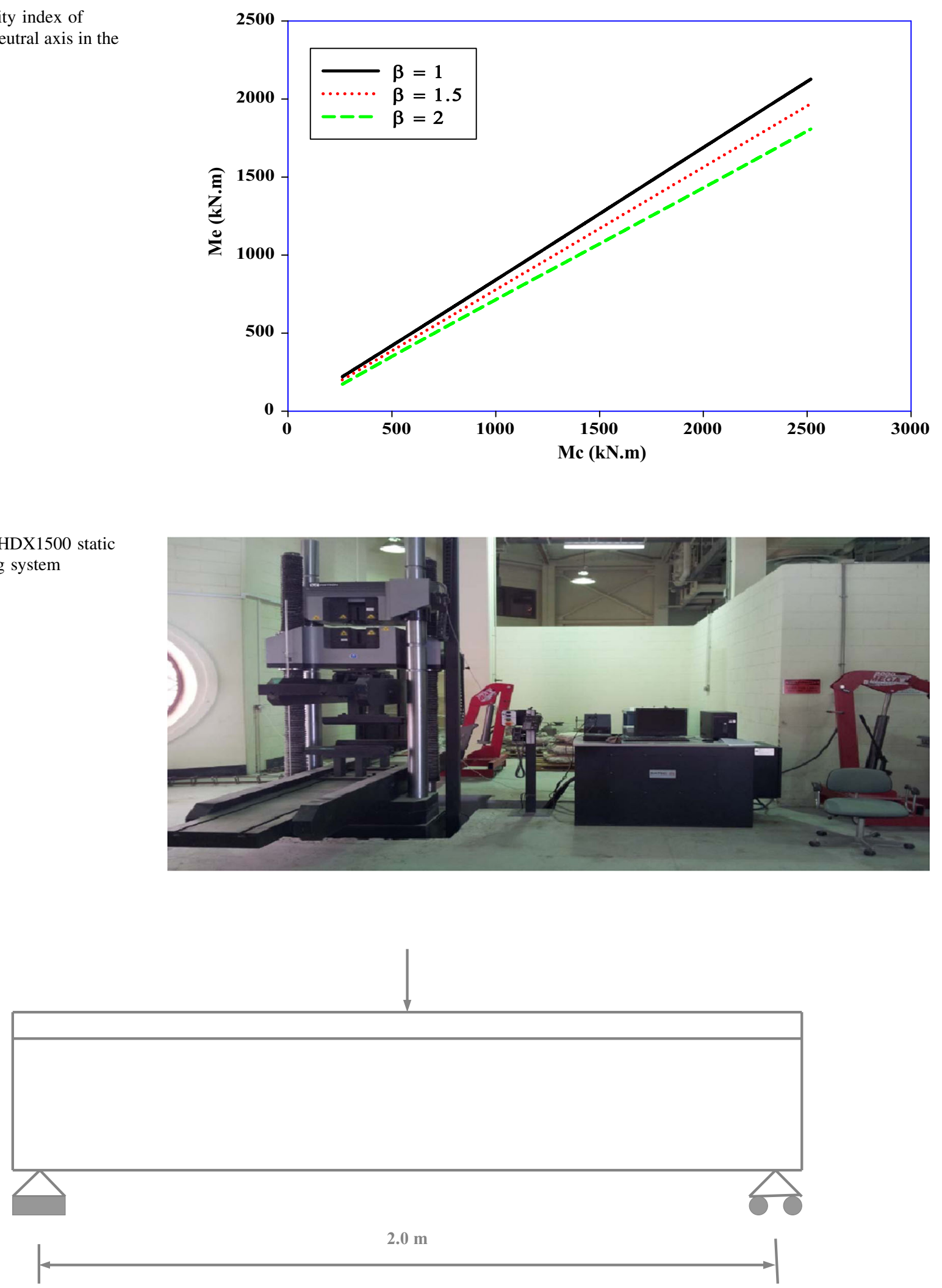

Fig. 6 Test setup schematic representation 
Table 4 Experimental beam dimensions

\begin{tabular}{lllllll}
\hline Beam type & $b_{\mathrm{w}}(\mathrm{mm})$ & $b_{\mathrm{f}}(\mathrm{mm})$ & $t_{\mathrm{f}}(\mathrm{mm})$ & $d(\mathrm{~mm})$ & $h(\mathrm{~mm})$ & Gross area $\left(\mathrm{mm}^{2}\right)$ \\
\hline T-beam & 150 & 350 & 50 & 170 & 200 & 40,000 \\
Triangular I & 250 & - & - & 187 & 217 & 27,125 \\
Triangular II & 300 & - & - & 230 & 260 & 39,000 \\
\hline
\end{tabular}

Table 5 Concrete mix design

\begin{tabular}{lllll}
\hline & Coarse aggregates $(\mathrm{kg})$ & Fine aggregates $(\mathrm{kg})$ & Cement $(\mathrm{kg})$ & Water $(\mathrm{kg})$ \\
\hline Weight per $\mathrm{m}^{3}$ of concrete & 1076 & 709 & 348 & 201 \\
\hline
\end{tabular}

Table 6 Testing machine output results

\begin{tabular}{llllllllll}
\hline $\begin{array}{l}\text { Time } \\
(\mathrm{s})\end{array}$ & $\begin{array}{l}\text { Extension } \\
(\mathrm{mm})\end{array}$ & Strain $(\%)$ & Load $(\mathrm{N})$ & $\begin{array}{l}\text { Flexure } \\
\text { stress } \\
(\mathrm{MPa})\end{array}$ & $\begin{array}{l}\text { Flexure } \\
\text { extension } \\
(\mathrm{mm})\end{array}$ & $\begin{array}{l}\text { Flexure } \\
\text { strain }(\%)\end{array}$ & $\begin{array}{l}\text { Flexure } \\
\text { load }(\mathrm{N})\end{array}$ & $\begin{array}{l}\text { Displacement } \\
(\mathrm{m})\end{array}$ & $\begin{array}{l}\text { Corrected } \\
\text { position }(\mathrm{mm})\end{array}$ \\
\hline 1.1 & 0.002 & $3.47 \mathrm{E}-06$ & 387.1283 & -0.11769 & -0.004 & -0.00017 & -387.1283 & $6.94 \mathrm{E}-06$ & 0.002 \\
1.2 & 0.002 & $5.96 \mathrm{E}-05$ & 386.4234 & -0.11747 & -0.004 & -0.00017 & -386.4234 & $1.19 \mathrm{E}-04$ & 0.002 \\
0.8 & -0.001 & $2.84 \mathrm{E}-05$ & 383.9681 & -0.11673 & -0.001 & $-4.16 \mathrm{E}-05$ & -383.9681 & $5.69 \mathrm{E}-05$ & -0.001 \\
1.8 & -0.002 & $1.04 \mathrm{E}-06$ & 383.6979 & -0.11664 & $-3.26 \mathrm{E}-19$ & $-1.36 \mathrm{E}-20$ & -383.6979 & $2.09 \mathrm{E}-06$ & -0.001 \\
0.7 & 0.000 & $4.12 \mathrm{E}-05$ & 382.4292 & -0.11626 & -0.002 & $-8.31 \mathrm{E}-05$ & -382.4292 & $8.25 \mathrm{E}-05$ & 0.000 \\
1.5 & -0.001 & $-2.47 \mathrm{E}-06$ & 382.0063 & -0.11613 & -0.001 & $-4.16 \mathrm{E}-05$ & -382.0063 & $-4.94 \mathrm{E}-06$ & -0.001 \\
0.5 & -0.001 & $-6.55 \mathrm{E}-05$ & 381.9828 & -0.11612 & -0.001 & $-4.16 \mathrm{E}-05$ & -381.9828 & $-1.31 \mathrm{E}-04$ & -0.001 \\
$:$ & $:$ & $:$ & $:$ & $:$ & $:$ & $:$ & $:$ & $:$ & $:$ \\
$:$ & $:$ & $:$ & $:$ & $:$ & $:$ & $:$ & $:$ & $7.41 \mathrm{E}-03$ \\
494.8 & -15.125 & $3.71 \mathrm{E}-03$ & -41075.9900 & 12.48710 & 15.123 & 0.628380 & 41075.99 & -15.125 \\
493.6 & -14.889 & $3.67 \mathrm{E}-03$ & -41089.5000 & 12.49121 & 14.887 & 0.618730 & 41089.50 & $7.34 \mathrm{E}-03$ & -14.889 \\
494.2 & -15.012 & $3.70 \mathrm{E}-03$ & -41098.5400 & 12.49395 & 15.010 & 0.623684 & 41098.54 & $7.40 \mathrm{E}-03$ & -15.012 \\
495.1 & -15.179 & $3.68 \mathrm{E}-03$ & -41119.8400 & 12.50030 & 15.177 & 0.630623 & 41119.41 & $7.36 \mathrm{E}-03$ & -15.179 \\
494.1 & -14.993 & $3.72 \mathrm{E}-03$ & -41124.8700 & 12.50196 & 14.991 & 0.622895 & 41124.87 & $7.41 \mathrm{E}-03$ & -14.993 \\
494.7 & -15.106 & $3.65 \mathrm{E}-03$ & -41125.1500 & 12.50204 & 15.104 & 0.627590 & 41124.15 & $7.31 \mathrm{E}-03$ & -15.106 \\
495.2 & -15.198 & $3.78 \mathrm{E}-03$ & -41129.3500 & 12.50332 & 15.196 & 0.631413 & 41129.35 & $7.56 \mathrm{E}-03$ & -15.198 \\
494.6 & -15.089 & $3.74 \mathrm{E}-03$ & -41130.0800 & 12.50354 & 15.087 & 0.626884 & 41120.08 & $7.47 \mathrm{E}-03$ & -15.089 \\
\hline
\end{tabular}

The simple beam moment formula $\frac{P L}{4}$ was used to compute the external moment $M_{\mathrm{e}}$ for all the beams. The computed values of $M_{\mathrm{e}}$ for Triangular I, Triangular II, and T-beams were 17, 22.5, and $20.5 \mathrm{kN} \mathrm{m}$, respectively. Equations 4, 10, and 13 were used to compute the reliability index $\beta$ of the experimental beams. Figure 9 shows the variation of the reliability index $\beta$ with respect to the external moment $M_{\mathrm{e}}$. As shown in the figure, the values of the reliability index $\beta$ for the three beams were either negative or very close to zero at their respective collapse load.

Table 8 summarizes the flexural crack width results during beam testing. The results show that flexural crack width for the three beams was large ranging from 7 to $10 \mathrm{~mm}$ for the triangular I beam, $5 \mathrm{~mm}$ to $7 \mathrm{~mm}$ for the triangular II beam, and 6 to $11 \mathrm{~mm}$ for the T-beam.

\section{Finite element analysis}

A nonlinear finite element analysis was conducted using the commercial software STAAD-PRO V8i., to simulate the experimental beams shown in Fig. 10 (Zhang 2013; Yazdizadeh 2013; Rao and Rao 2012). Figures 11 and 12 shows the structural models of the triangular and T-beams, respectively. Solid and beam elements were used to model the concrete material and reinforcing steel bars, respectively. Geometric rather than material non-linearity (second-order analysis) was considered in this study. The failure criteria considered herein is the displacement.

Table 9 and Fig. 13 show the displacements of the three beams obtained using the finite element model and those obtained experimentally. The results show that the finite element vertical displacements compared well with those 


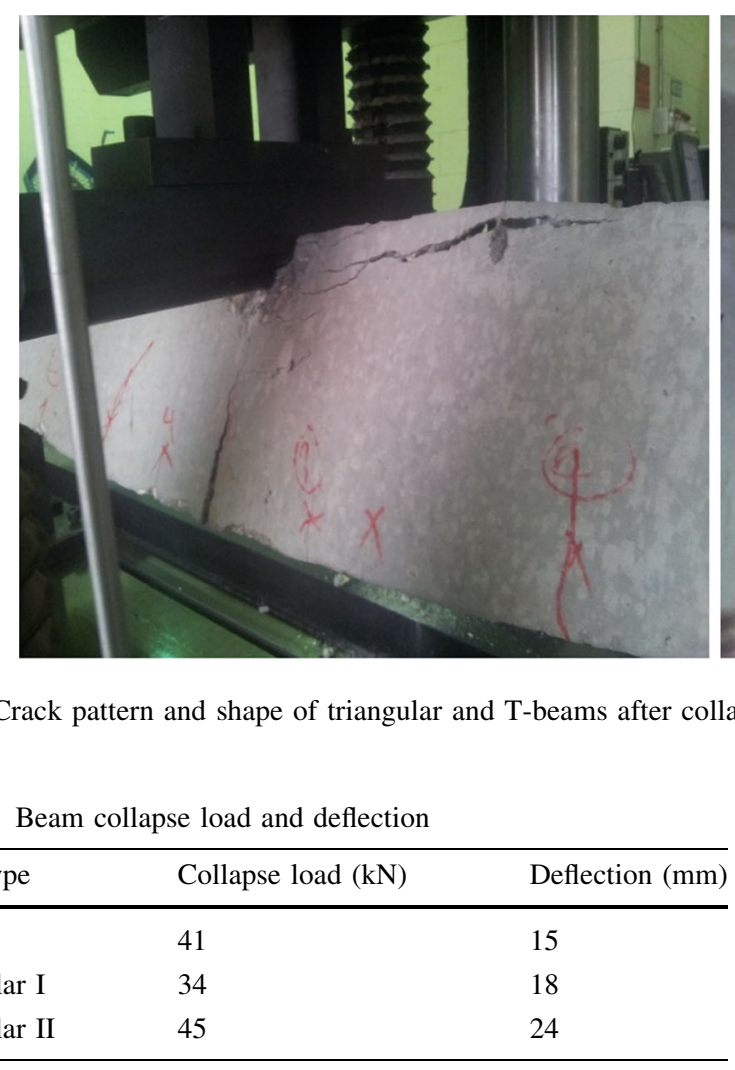

obtained experimentally. It is worth noting that horizontal and buckling displacements in the finite element model were set equal to $2.0 \mathrm{~mm}$ and zero, respectively. The results also show that the displacements obtained using the finite element model were larger than those obtained experimentally. In other words, the displacements obtained using the finite element method were more conservative than those obtained experimentally. This is an indication

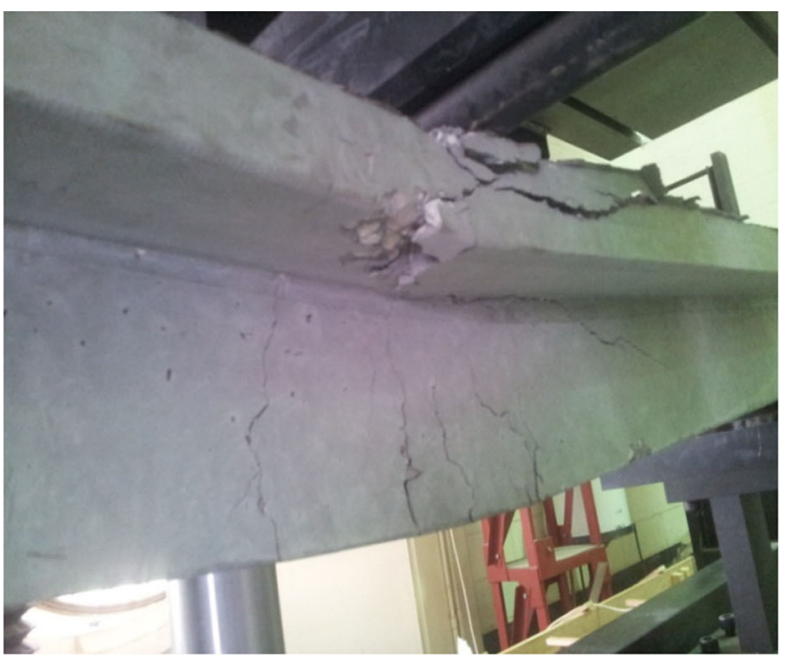

that the finite element method can provide reliable analysis results comparable to those obtained experimentally.

\section{Discussion}

Three reinforced concrete beams were tested experimentally and analyzed analytically using the finite element method. Their reliability was also assessed using the reliability index approach. The safety percentage values for the triangular beams were equal to 15,20 , and $26 \%$ for $\beta$ values of $1,1.5$ and 2 , respectively. On the other hand, the safety percentage values for the T-beam with the neutral axis in the flange were equal to 15,21 and $27 \%$ for $\beta$ values of $1,1.5$ and 2 , respectively. The safety percentage values for the T-beam with the neutral axis in the web were
Fig. 8 Beam load deflection response

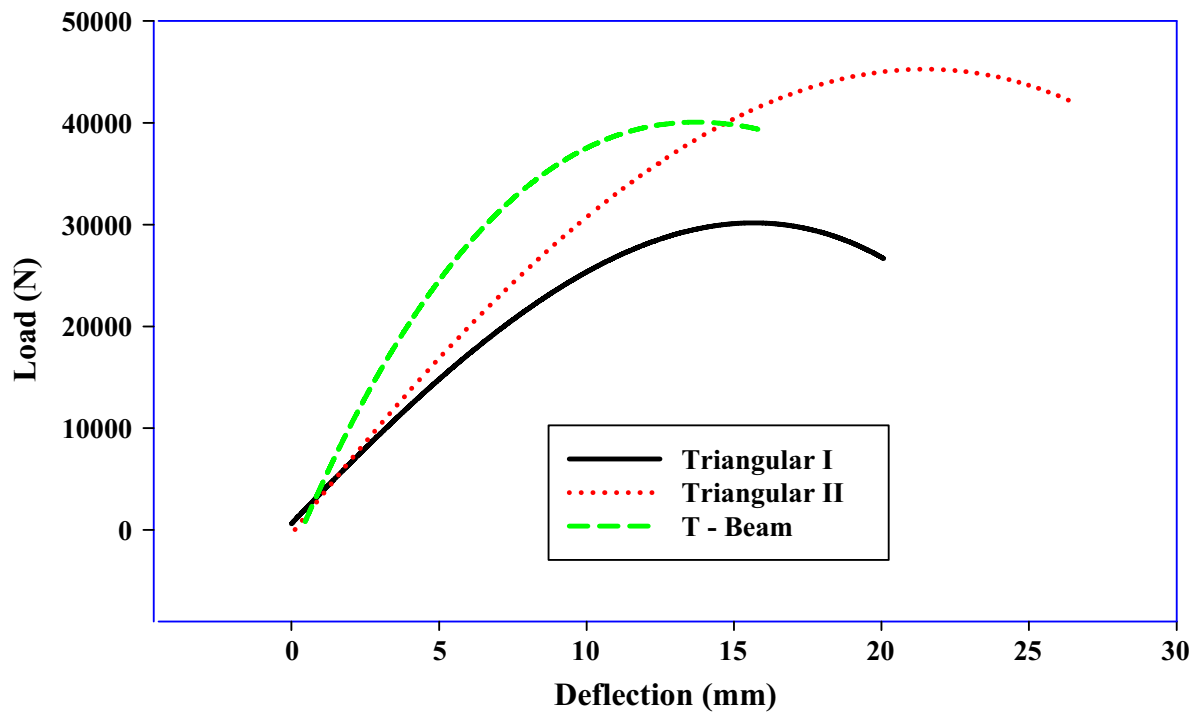


Fig. 9 Reliability index versus external moment for experimental beams

Table 8 Experimental beam cracking load and width

Fig. 10 Finite element solid models

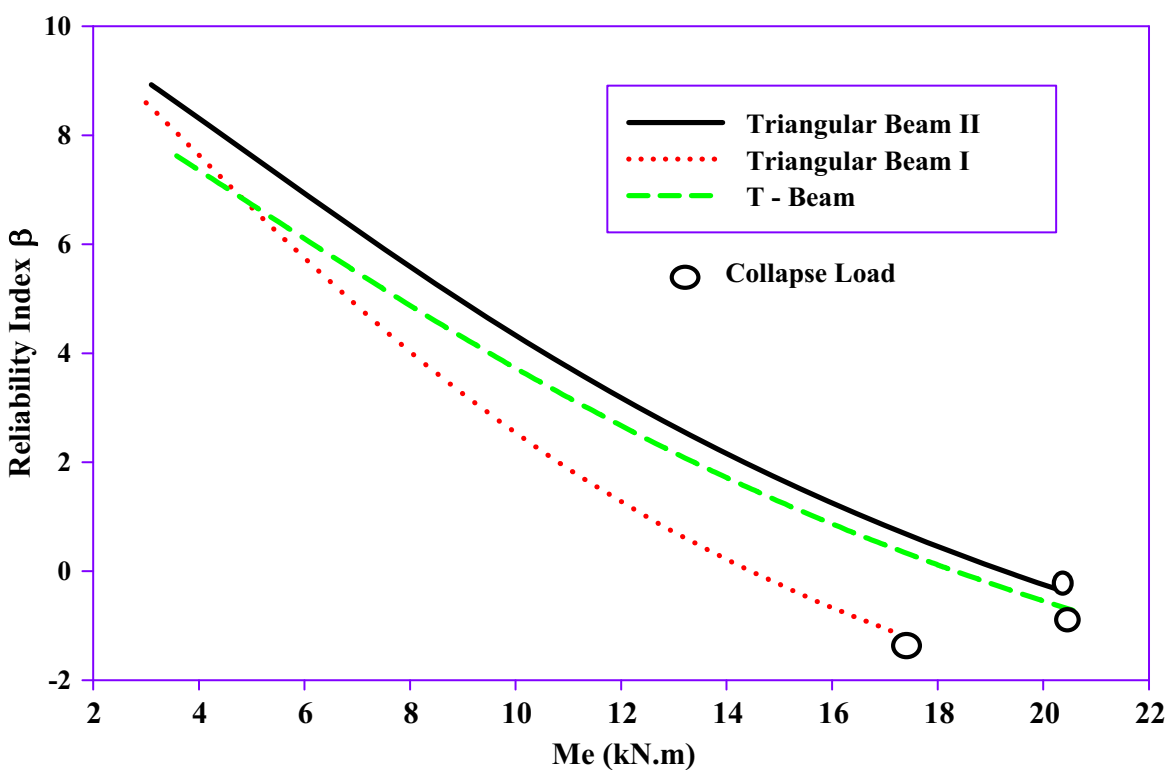

\begin{tabular}{|c|c|c|c|c|c|c|}
\hline \multirow[t]{2}{*}{ Beam type } & \multicolumn{2}{|l|}{ 1st crack } & \multicolumn{2}{|l|}{ 2nd crack } & \multicolumn{2}{|l|}{ 3rd crack } \\
\hline & Load $(\mathrm{kN})$ & Width (mm) & Load $(\mathrm{kN})$ & Width (mm) & Load $(\mathrm{kN})$ & Width (mm) \\
\hline Triangular I & 15.4 & 7 & 16.9 & 9 & 21.3 & 10 \\
\hline Triangular II & 20.7 & 5 & 23.1 & 6 & 26.2 & 7 \\
\hline T-beam & 13.6 & 6 & 14.9 & 8 & 19.1 & 11 \\
\hline
\end{tabular}

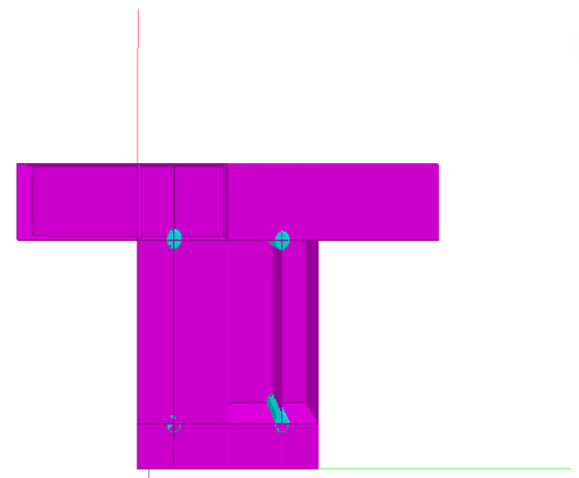

Triangular Beam

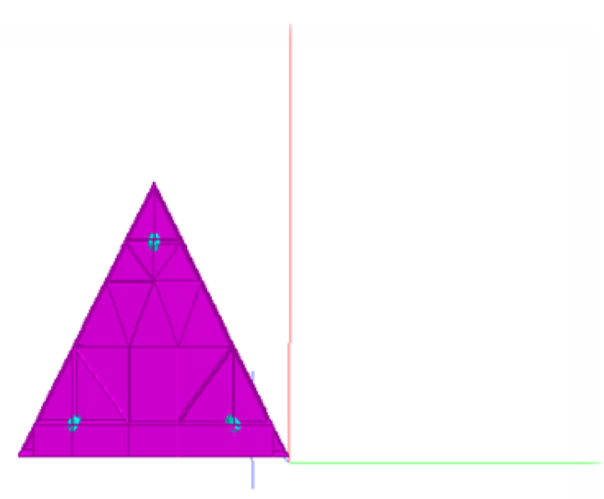

T- Beam equal to 16,22 , and $28 \%$ for $\beta$ equals $1,1.5$ and 2 , respectively. The experimental load-deflection response of the beams showed that the triangular beams had a better toughness and exhibited higher plastic deformation before failure. This is an indication that a T-beam would collapse faster than a triangular beam for an equal area of steel and concrete. The 1st, 2nd, and 3rd cracks showed that the Triangular-II beam exhibited smaller cracks than did the T-beam for larger loads even though it had a smaller concrete gross area. The design moment strength $M_{\mathrm{c}}$ that was computed using the experimental collapse loads were 20.5, 17 and $22.5 \mathrm{kN}$ m for the T-beam, Triangular-I beam, and Triangular-II beam, respectively. The design moment strength $M_{\mathrm{c}}$ computed using the ACI design code were $18.35,14.45$, and $21.6 \mathrm{kN} \mathrm{m}$ for the T-beam, Triangular-I beam, and Triangular-II beam, respectively. The reliability analysis of the experimental data predicted a low reliability index $\beta$ of $-0.6,-1.0$ and -0.4 at the collapse load for the T-beam, Triangular-I and Triangular-II, respectively. The finite element beam displacement at the collapse load was 
Fig. 11 Triangular beam structural model

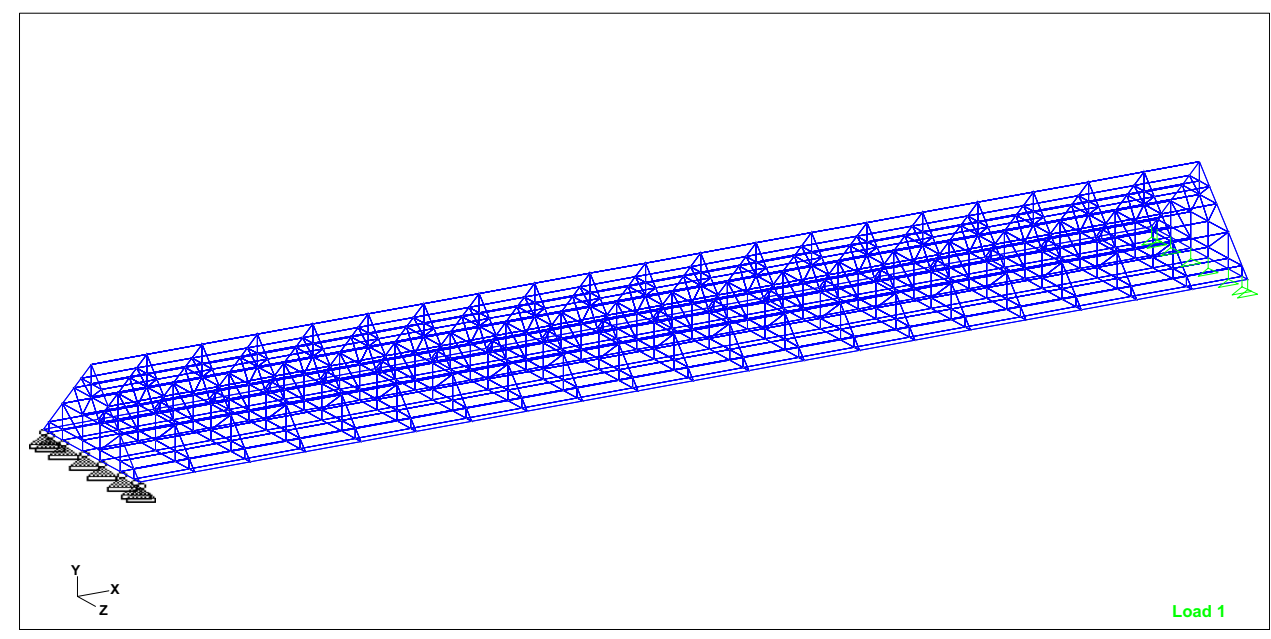

Fig. 12 T-beam structural model

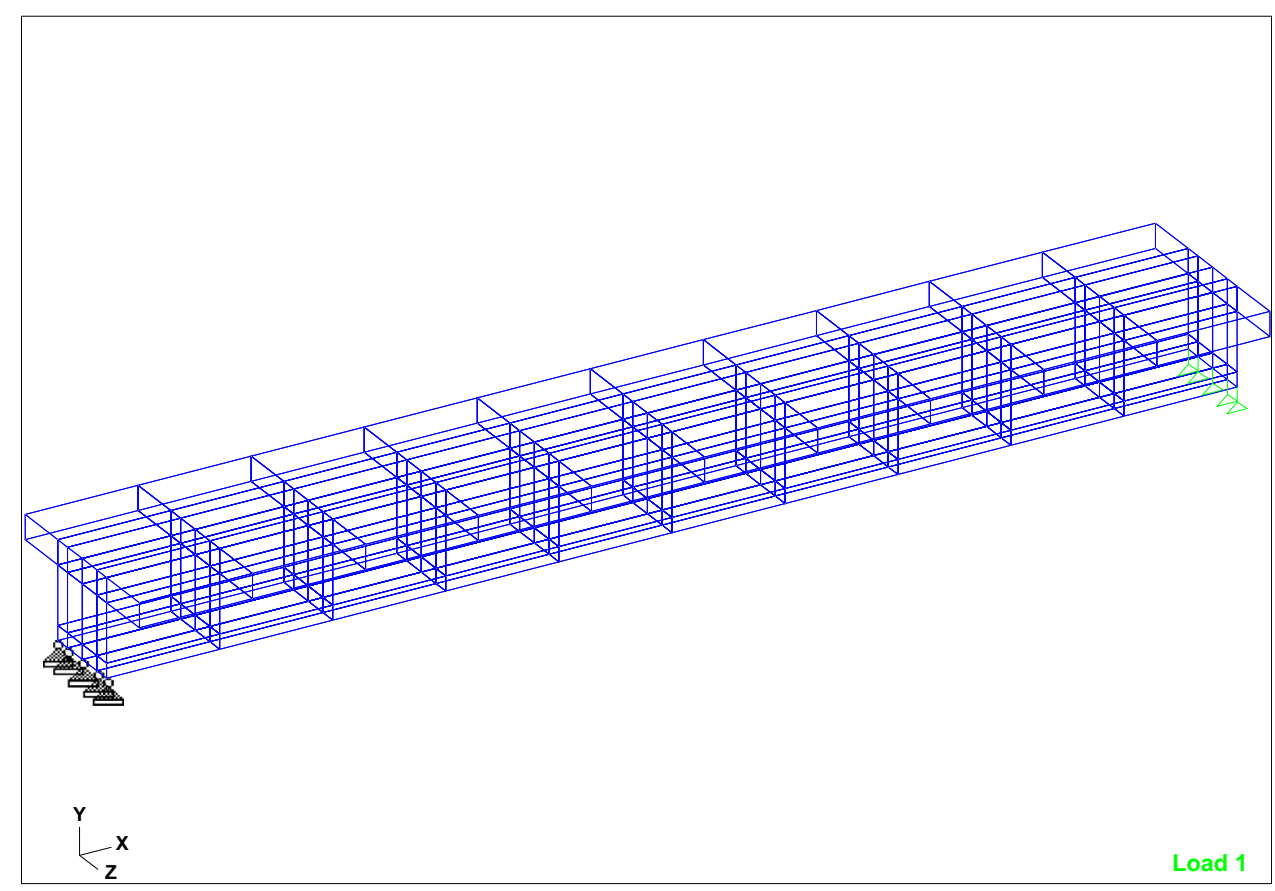

\begin{tabular}{|c|c|c|c|c|c|}
\hline \multirow[t]{2}{*}{ Beam type } & \multirow[t]{2}{*}{ Collapse load $(\mathrm{kN})$} & \multicolumn{3}{|c|}{ Finite element dispacements } & \multirow{2}{*}{$\begin{array}{l}\text { Experimental displacement } \\
\delta_{\text {VEXP }}(\mathrm{mm})\end{array}$} \\
\hline & & $\delta_{\mathrm{HFE}}(\mathrm{mm})$ & $\delta_{\mathrm{VFE}}(\mathrm{mm})$ & $\delta_{\mathrm{ZFE}}(\mathrm{mm})$ & \\
\hline T-beam & 41 & 2 & 17 & 0 & 15 \\
\hline Triangular-I & 34 & 2 & 24 & 0 & 18 \\
\hline Triangular-II & 45 & 2 & 26 & 0 & 24 \\
\hline
\end{tabular}

Table 9 Beam finite element model and experimental displacements

\section{Conclusions}

larger than the experimental one by 11,25 , and $7 \%$ for the T-beam, Triangular-I, and Triangular-II, respectively. These percentages indicate that the finite element nonlinear analysis is safe and yields results that are close to those obtained experimentally, provided that the maximum allowed horizontal displacement is limited to $2.0 \mathrm{~mm}$ and no buckling displacement is allowed.
The paper studied the behavior of triangular and T-reinforced concrete beams. Numerical and experimental studies were conducted to study the behavior of simply supported triangular and T-beams. Their reliability was also assessed using the reliability index approach. The 
Fig. 13 Experimental and finite element beam responses

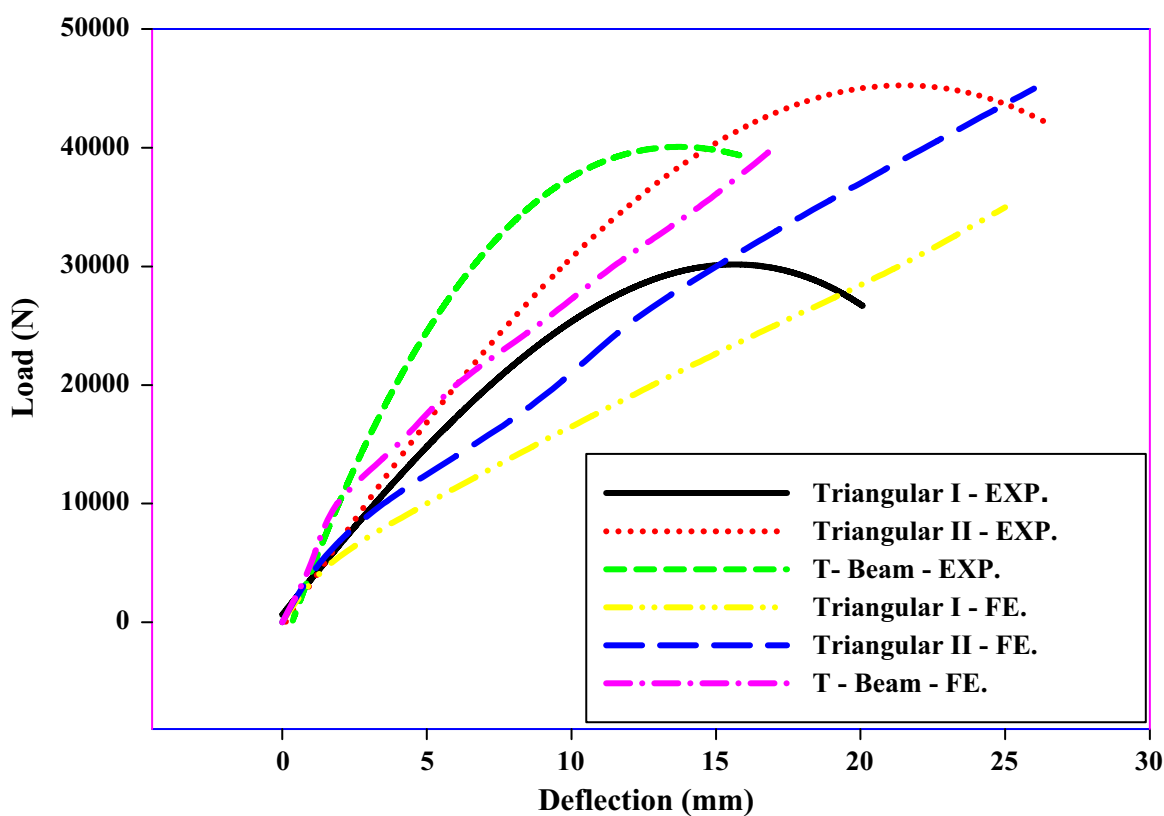

results showed that the vertical displacements that were computed using the finite element method compared well with those obtained experimentally. The difference between the displacements obtained using the finite element model and those obtained experimentally was larger than $8 \%$. In other words, the displacements obtained using the finite element analysis were conservative. This is an indication that the finite element method can provide reliable analysis results comparable to those obtained experimentally. The results showed that the triangular beams exhibited higher ductility at failure than did the T-beam. The displacements of the triangular beams I and II at collapse were approximately 26 and $21 \mathrm{~mm}$, respectively. On the other hand, the displacement of the T-beam at collapse was approximately $17 \mathrm{~mm}$. This shows that the plastic deformations at failure of the triangular beams were higher than that of the T-beam. This is a strong indication of the higher ductility of the triangular beams compared to the T-beam. Triangular beams have smaller cracks under large loads than do T-beams for equal areas of steel and concrete. The design moment strengths $M_{c}$ computed using the ACI design code formulation were safe and close to those computed using experimental results. The experimental results verified the assessment of the reliability analysis that stated that the triangular beams are more reliable than T-beams for equal areas of steel and concrete.

Open Access This article is distributed under the terms of the Creative Commons Attribution 4.0 International License (http://creative commons.org/licenses/by/4.0/), which permits unrestricted use, distribution, and reproduction in any medium, provided you give appropriate credit to the original author(s) and the source, provide a link to the Creative Commons license, and indicate if changes were made.

\section{References}

Al-Ansari MS (2013a) Reliability index of tall buildings in earthquake zones. Open J Earthq Eng Res 2:39-46

Al-Ansari MS (2013b) Flexural safety cost of optimized reinforced concrete beams. Int J Civ Eng Technol 4:15-35

American Concrete Institute (ACI) (2008). Building code and commentary. ACI-318M-08, Detroit

Bentley System Inc. (2009) STAAD PRO V8i. Three dimensional static and dynamic finite element analysis and design of structures. 2700 Savi Ranch Pkwy, Yorba Linda, CA 92887-4608

Borse K, Dubey W (2013) Geometric linear and nonlinear analysis of beam. Int J Eng Res Technol 2:415-423

Instron (2003) Universal Testing System, 825 University Ave., Norwood, MA 02062-2643

Lu R, Luo Y, Conte J (1994) Reliability evaluation of reinforced concrete beams. Struct Saf 14:277-298

McCormac JC, Brown RH (2009) Design of reinforced concrete, 8th edn. Wiley, New Jersey

Nahvi H, Jabbari M (2005) Crack detection in beams using experimental modal data and finite element model. Int J Mech Sci 47:1477-1497

Nowak AS, Collins KR (2013) Reliability of structures. CRC Press, New York

Rao P, Rao V (2012) A study on load—deflection behavior of cracked concrete beam using FEM: fracture mechanics approach. Int $\mathbf{J}$ Eng Res Technol 1(6):1-8

Saifullah M, Nasir U, Udin S, Rashid M (2011) Experimental and analytical investigation of flexural behavior of reinforced concrete beam. Int J Eng Technol 11:188-196

Vecchio F, Shim W (2004) Experimental and analytical reexamination of classic concrete beam tests. J Struct Eng ASCE 130:460-469

Yazdizadeh Behrooz (2013) Analyzing some behavior of a beam with different crack positions transversely inside it. J Sci Res 5:56-60

Zhang C (2013) Using finite element software to simulation fracture behavior of three-point bending beam with initial crack. J Softw $8: 1145-1150$ 